\title{
Comparative Outcome of Oral and Subcutaneous Methotrexate Therapy in Children with Juvenile Idiopathic Arthritis
}

\author{
Mamun Miah, ${ }^{7}$ Kazi Zahidul Hoque, ${ }^{2}$ Akhand Tanzih Sultana, ${ }^{3}$ Md. Zahangir Alam, ${ }^{4}$
}

\begin{abstract}
Background \& objective: Juvenile idiopathic arthritis (JIA) is the most disabling illness in children. There are number of disease modifying antirheumatic drugs (DMRDS). Methotrexate (MTX) is one of them and for the last two decades has become the cornerstone for the treatment of JIA, because of its efficacy and safety profile. However, debate is still continuing regarding its route of administration (orally or parenteraly) to have wider efficacy and safety. The present study was conducted to compare the outcome of oral and subcutaneous MTX in the treatment of JIA.
\end{abstract}

Materials \& Methods: This comparative clinical trial was conducted in Dhaka Shishu Hospital \& Bangladesh Institute of Child Health, over a period of 3 years between January 2013 to December 2015. The study initially included 72 children; of them 22 dropped out or did not comply with treatment protocol and hence were excluded from final analysis. Of the remaining children 25 were in Oral and 25 in subcutaneous group. Primary outcome was defined as the percentage of patients reaching ACR Pedi 30 improvement criteria after 6 months of treatment. The ACR Pedi 30 was reached if there was an improvement of $\geq 30 \%$ in at least 3 of 6 core variables, with no worsening of $>1$ of the remaining variables by $\geq 30 \%$.

Results: The study demonstrated that children with JIA responded well to MTX treatment irrespective of their route of administration, as was evidenced by the achievement of ACR Pedi 30 criteria by majority of the children after 6 months of treatment. However, in terms of core set of variables, subcutaneous route worked better and faster than the oral route. The mean numbers of active joints in the Oral group dropped from 5 at baseline to nearly 2 and $<2$ at 3 and 6 months respectively, which in the Subcutaneous groups dropped from 6 at baseline to 2 and $<1$ at 3 and 6 months respectively. The average numbers of joints with limited range of motion at baseline in the Oral and Subcutaneous groups were 3 and $>3$ which decreased to 1 and $<1$ respectively at month 6 . Likewise patient/parents' global assessment of overall wellbeing improved earlier in Subcutaneous group than that in the Oral group $(p<0.001)$. Physician's global assessment of disease activity also responded better in the subcutaneous group compared to that in the Oral group $(p<0.001)$. The C-HAQ disability index in the Oral group reduced insidiously from 1.3 at baseline to 0.4 at 6 months; in contrast the same parameter steeply decreased from 1.5 at baseline to 0.0 at 6 months indicating that Children Health Assessment Questionnaire responded rapidly to Subcutaneous MTX. The ESR in Oral group decreased from 79 at baseline to $<40$ at month 3 and to close to $30 \mathrm{~mm}$ at month 6 , which in the Subcutaneous group decreased from over 70 at baseline to $<30$ and $<20$ at month 3 and 6 respectively indicating that the decrease being much faster in the latter group.

Conclusion: The study concluded that children with JIA responded well to MTX treatment irrespective of their route of administration, as was evidenced by the achievement of ACR Pedi 30 criteria by majority of the children after 6 months of treatment. However, considering the response in terms of core set of variables, it appears that subcutaneous route worked better and faster than the oral route did.

Key words: Juvenile idiopathic arthritis, methotrexate, oral route, subcutaneous route, ACR 30 criteria etc.

\section{Authors' information:}

${ }^{1}$ Dr. Mamun Miah, Assistant Professor, Department of Paediatric Rheumatology, Bangladesh Institute of Child Health (BICH), Dhaka Shishu (Children) Hospital.

${ }^{2}$ Dr. Kazi Zahidul Hoque, Assistant Professor, Department of Paediatric Cardiac Surgery, Bangladesh Institute of Child Health. (BICH), Dhaka Shishu (Children) Hospital.

${ }^{3}$ Dr. Akhand Tanzih Sultana, Assistant Professor, Department of Paediatric Pulmonology, Bangladesh Institute of Child Health (BICH), Dhaka Shishu (Children) Hospital.

${ }^{4}$ Dr. Md. Zahangir Alam, Professor \& Head, Department of Paediatric Rheumatology, Bangladesh Institute of Child Health (BICH), Dhaka Shishu (Children) Hospital.

Correspondence: Mamun Miah, Cell phone: +880 1913-162493,E-mail: torsa_mahin@yahoo.com 


\section{INTRODUCTION}

Juvenile idiopathic arthritis (JIA) is a collective term for different entities of diseases with arthritis starting before the age of 16 years. ${ }^{1}$ With an incidence of 19.8 per 100,000 children age $\leq 16$ years, JIA is the most common chronic inflammatory disease in childhood and can lead to severe disability. ${ }^{2,3}$ The medical treatment of JIA consists of a variety of disease-modifying antirheumatic drugs (DMARDs). Of them nonsteroidal antirheumatic drugs are mainly used for symptomatic relief and DMARDs to control the clinical activity of the disease. ${ }^{4}$ Of the latter group, methotrexate (MTX) is the most commonly used drug for the treatment of polyarticular JIA patients. Its efficacy was established in a double blind, randomized, placebo controlled trial by Giannini and co-workers two and a half decades ago. ${ }^{5}$ Since then a number controlled clinical trials have been done aimed at defining more precisely the effectiveness and toxicity profile of this drug in JIA and it has emerged as the most common first-line DMARD treatment. ${ }^{6-10}$

However, till now there is no consensus as to which route of administration is to be preferred to ensure a better efficacy and safety profile in children. While a controlled prospective study comparing oral versus parenteral administration in adult patients with rheumatoid arthritis (RA) showed significantly higher American College of Rheumatology (ACR) 20\% and $70 \%$ improvement criteria response rates in patients with parenteral MTX, there are not enough studies to recommend its use in JIA patients in a particular route. ${ }^{11}$ Two studies reported successful use of parenteral MTX treatment in patients of JIA who failed oral treatment. ${ }^{7,12}$ Klein et al. ${ }^{13}$ in a retrospective study from the German Methotrexate Registry for the long-term treatment of JIA with MTX, did not find any superiority (in terms of efficacy and tolerability) of subcutaneous MTX over oral MTX.

The question of how to start treatment with methotrexate (MTX) in children with JIA, orally or subcutaneously, is of great importance. Especially for pediatric patients, the injections can be painful, may pose a significant burden for the patients and their parents, and may result in more consultations of physicians or health professionals. On the other hand the bioavailability of oral MTX in adult patients with RA is highly variable and, on an average, is two-thirds that of subcutaneous (SC) administration. ${ }^{14,15}$ Taken together, there is strong evidence that MTX is the standard DMARD therapy for patients with JIA. But, it is not clear which route of administration is the better. Comparative prospective studies are, therefore, especially needed. That purpose the present study was undertaken to compare the outcome (in terms of clinical efficacy and safety) of SC versus oral administration of MTX in patients with active JIA.

\section{MATERIALS AND METHODS:}

This comparative clinical trial was conducted in Dhaka Shishu Hospital \& Bangladesh Institute of Child Health over a period of 3 years between January 2013 to December 2015. Before commencing the study, ethical clearance was sought from Ethical Review Committee of the Institute. The children admitted with JIA according to the published criteria $^{1}$ were the study population. Only those patients whose parents gave written consent to start long-term treatment with MTX were enrolled. However, children with a history of or concomitant therapy with biologic agents were excluded. A total of 72 children were included and were randomly assigned to subcutaneous MTX $(n=36)$ and oral MTX $(n=36)$ groups. In both groups the dose of MTX used was 10 $\mathrm{mg} / \mathrm{m} 2 /$ weekly. 15 children dropped out or violated the treatment protocol in the first 3 months and 7 in the next 3 months of treatment leaving 25 children in each group. The analyses were performed 25 children in each group, who were interested to get treatment.

Before start of treatment with MTX, data were collected from medical records, and patients were assessed clinically. Laboratory investigations were done routinely and results were documented. The following data were collected at baseline: age at start of treatment, sex, duration of disease, JIA subtype, previous medical history, previous and current treatments, date of first dose of MTX, prescribed dose of MTX, clinical assessment including weight, height, joint assessment, general examination, physician global assessment of disease activity, and parent/patient global assessment of overall well-being, with measures being a $10-\mathrm{cm}$ visual analog scale (VAS), Childhood Health Assessment Questionnaire (C-HAQ), erythrocyte sedimentation rate (ESR), and C-reactive protein level. At 3 and 6 months 
after the start of therapy, the following data were collected: dose of MTX, missed doses of MTX, concomitant treatment, adverse events (AEs), and clinical and laboratory tests as described above. In case of discontinuation, the date of the last dose of MTX and reasons for withdrawal was documented. The reasons were recorded as intolerance, non-respondents, remission, or other reasons. Six core set of parameters were evaluated in this study, which consisted of 1 ) physician global assessment of disease activity $(10-\mathrm{cm}$ VAS); 2) parent/patient global assessment of overall well-being (10-cm VAS); 3) the C-HAQ, a measure of physical function; 4) the number of joints with active arthritis, defined by the presence of swelling or, if no swelling is present, the limitation of motion accompanied by pain, tenderness, or both; 5) the number of joints with limited range of motion; and 6 ) the ESR.

Primary outcome was defined as the percentage of patients reaching ACR Pedi 30 improvement criteria after 6 months of treatment. The ACR Pedi 30 was reached if there was an improvement of $\geq 30 \%$ in at least 3 of 6 core variables, with no worsening of $>1$ of the remaining variables by $\geq 30 \% .16$ Nonresponders were defined as patients not reaching at least ACR Pedi 30 response or patients who discontinued treatment due to inefficacy or intolerance. Safety was defined as the number of patients with AEs and the number of withdrawals. An AE was defined as any unfavorable and unintended sign including an abnormal laboratory finding, symptom, or disease that occurred during MTX treatment. Serious AEs were defined as events that were fatal or life threatening, resulted in a persistent or significant disability or incapacity, required prolonged inpatient hospitalization.

The statistical analyses were performed using computer software SPSS (Statistical Package for Social Sciences), version 17 and test statistics used to analyse the data were Chi-square $\left(\chi^{2}\right)$ Test, Unpaired t-Test and Repeated Measure ANOVA. While categorical data were compared between groups using Chi-square $\left(\chi^{2}\right)$ or Fisher's Exact Test, as appropriate, changes in continuous variables following intervention were evaluated using Repeated Measure ANOVA and/or Unpaired t-Test. The level of significance was set at $5 \%$ and $p<0.05$ was considered significant.

\section{RESULTS:}

\section{Baseline characteristics:}

At entry there was no significant difference between the study groups in terms of age with mean ages of Oral and Subcutaneous groups being 5.3 and 4.8 years respectively $(p=0.330)$. Sex and weight distributions were almost identical between the groups $(p=0.395, p$ $=0.883$ ). The mean duration of disease was $>1$ year in either group ( $p=0.891)$. The type of arthritis was also similar in both groups $(p=0.906)$. Of the six core set of parameters, there were no significant differences in active joint counts, number of joints with limited range of motion, and C-HAQ scores, parent/patient global assessment of overall well-being, and ESR between the 2 cohorts. However, patients of oral MTX treatment group had significantly higher scores for physician global assessment of disease activity $(p=0.011)$ (Table I).

\begin{tabular}{|c|c|c|c|}
\hline \multirow[b]{2}{*}{ Baseline characteristics } & \multicolumn{2}{|c|}{ Group } & \multirow[b]{2}{*}{ p-value } \\
\hline & $\begin{array}{c}\text { Oral } \\
(n=25)\end{array}$ & $\begin{array}{l}\text { Subcutaneous } \\
\qquad(n=25)\end{array}$ & \\
\hline Age at start of treatment (years) & $5.3 \pm 1.7$ & $4.8 \pm 1.9$ & 0.330 \\
\hline \multicolumn{4}{|l|}{ Sex } \\
\hline Male & $10(40.0)$ & $13(52.0)$ & \multirow{2}{*}{0.395} \\
\hline Female & $15(60.0)$ & $12(48.0)$ & \\
\hline Weight (kg) & $14.9 \pm 2.9$ & $14.8 \pm 2.9$ & 0.883 \\
\hline Duration of diseases (years) & $1.1 \pm 0.5$ & $1.1 \pm 0.9$ & 0.891 \\
\hline \multicolumn{4}{|l|}{ JIA subtype } \\
\hline RF negative polyarthritis & $9(36.0)$ & $8(32.0)$ & \multirow{5}{*}{0.906} \\
\hline Persistent oligo-arthritis & $8(32.0)$ & $7(28.0)$ & \\
\hline Enthesitis-related arthritis & $3(12.0)$ & $2(8.0)$ & \\
\hline Systemic arthritis & $3(12.0)$ & $5(20.0)$ & \\
\hline Others & $2(8.0)$ & $3(12.0)$ & \\
\hline \multicolumn{4}{|l|}{ Disease activity: } \\
\hline Number of joints with active arthritis & $4.9 \pm 1.5$ & $5.5 \pm 1.7$ & 0.204 \\
\hline No. of joints with limited range of motion & $3.0 \pm 1.3$ & $3.2 \pm 0.9$ & 0.461 \\
\hline Patient/Parents' global assessment $(0-10 \mathrm{~cm})$ & ) $6.8 \pm 1.1$ & $6.2 \pm 0.9$ & 0.060 \\
\hline Physician's global assessment $(0-10 \mathrm{~cm})$ & $6.6 \pm 1.2$ & $5.8 \pm 0.8$ & 0.011 \\
\hline C-HAQ disability index $(0-3 \mathrm{~cm}))$ & $1.3 \pm 0.8$ & $1.5 \pm 0.5$ & 0.212 \\
\hline $\operatorname{ESR}(\mathrm{mm})$ & $78.6 \pm 20.6$ & $71.2 \pm 17.4$ & 0.177 \\
\hline
\end{tabular}

\section{Previous and current medication:}

History of previous medication revealed that Naproxan was the most frequently used drug in oral MTX group (92\%) compared to subcutaneous group (52\%). Indomethacin and aspirin were seldom used by the oral group. Of the current medications concomitantly used with MTX, folic acid was invariably used by either group 
(100\%) followed by Naproxan and prednisolone. There was no significant difference between the groups in terms of current medications concomitantly used with MTX ( $p>0.05)$ (Table II).

\begin{tabular}{|c|c|c|}
\hline \multicolumn{3}{|c|}{$\begin{array}{l}\text { TABLE II. Distribution of baseline characteristics between } \\
\text { the study groups }\end{array}$} \\
\hline \multirow[b]{2}{*}{ History of medications } & \multicolumn{2}{|c|}{ Group } \\
\hline & $\begin{array}{c}\text { Oral } \\
(n=25)\end{array}$ & $\begin{array}{l}\text { Subcutaneous } \\
\qquad(n=25)\end{array}$ \\
\hline \multicolumn{3}{|l|}{ Previous medications } \\
\hline Indomethacin & $2(8.0)$ & $4(16.0)$ \\
\hline Naproxen & $23(92.0)$ & $13(52.0)$ \\
\hline Aspirin & $2(8.0)$ & $5(20.0)$ \\
\hline Others & $20(80.0)$ & $20(80.0)$ \\
\hline \multicolumn{3}{|l|}{ Current medications } \\
\hline Folic acid & $25(100.0)$ & $25(100.0)$ \\
\hline Prednisolon & $13(52.0)$ & $10(40.0)$ \\
\hline Naproxen & $19(76.0)$ & $18(72.0)$ \\
\hline Others & $14(56.0)$ & $2(8.0)$ \\
\hline
\end{tabular}

Changes in disease activity following intervention: The mean numbers of active joints at the beginning of treatment in the Oral and Subcutaneous groups were 4.9 and 5.5 respectively which reduced to 2.2 and 1.9 respectively at 3 months and 1.6 and 0.5 respectively at 6 months of treatment. Although both groups responded to treatment, the response was significantly faster in the subcutaneous group $(p=0.001)$. The average numbers of joints with limited range of motion at baseline in the Oral and Subcutaneous groups were 3 and $>3$ which decreased to 1.2 and 0.9 respectively at month 3 and to 1.0 and 0.5 respectively at month 6 ( $p$ $=0.035$ ). Likewise patient $/$ parents' global assessment of overall wellbeing, measured with $10-\mathrm{cm}$ visual analog scale (VAS), were reduced from 6.8 at baseline to 4.2 at 3 months and $3.6 \mathrm{~cm}$ at 6 months in Oral group and from 6.2 at baseline to 2.3 at 3 months and 1.5 at 6 months in Subcutaneous group respectively with response being appreciably better in the latter group ( $p$ $<0.001$ ). Physician's global assessment of disease activity, also measured in $10 \mathrm{~cm}$ VAS, responded better in the subcutaneous group with reduction being more pronounced in the subcutaneous group (from 5.5 at baseline to $1.6 \mathrm{~cm}$ at 6 months) than that in the oral group (from 5.8 at baseline to $1.4 \mathrm{~cm} 6$ months) ( $p<$ 0.001 ). The C-HAQ disability index in the Oral group gradually reduced from 1.3 at baseline to 0.8 and 0.4 at
3 and 6 months respectively, whereas the same parameter steeply reduced from 1.5 at baseline to 0.7 and 0.0 at 3 and 6 months respectively $(p=0.002)$. The ESR in Oral group decreased from 78.6 at baseline to 39.7 at month 3 and $30.2 \mathrm{~mm}$ at month 6 , which in the Subcutaneous group decreased from 71.2 at baseline to 26.6 and $19.7 \mathrm{~mm}$ at month 3 and 6 respectively with decrease being demonstrably faster in the latter group $(p=0.001)$ (Table III-IV \& Fig. 1-6).

\begin{tabular}{|c|c|c|c|}
\hline \multirow{2}{*}{$\begin{array}{l}\text { Variables measuring } \\
\text { disease activity }\end{array}$} & \multicolumn{2}{|c|}{ Group } & \multirow[b]{2}{*}{$p$-value } \\
\hline & $\begin{array}{c}\text { Oral } \\
(n=25)\end{array}$ & $\begin{array}{l}\text { Subcutaneous } \\
\qquad(\mathrm{n}=25)\end{array}$ & \\
\hline Number of joints with active arthritis & $2.2 \pm 1.5$ & $1.9 \pm 1.4$ & 0.580 \\
\hline Number of joints with limited range of motion & n $1.2 \pm 1.0$ & $0.9 \pm 0.7$ & 0.224 \\
\hline Patient/Parents' global assessment $(0-10 \mathrm{~cm})$ & $4.2 \pm 1.6$ & $2.3 \pm 1.9$ & $<0.001$ \\
\hline Physician's global assessment (0-10) & $3.9 \pm 2.0$ & $2.4 \pm 2.0$ & 0.008 \\
\hline C-HAQ disability index (0-3) & $0.8 \pm 0.6$ & $0.7 \pm 0.4$ & 0.458 \\
\hline ESR & $39.7 \pm 12.4$ & $26.6 \pm 8.8$ & $<0.001$ \\
\hline
\end{tabular}

TABLE III. Comparison of disease activity after 6 months of intervention with MTX

\begin{tabular}{lccc} 
Variables measuring disease & \multicolumn{2}{c}{ Group } & \\
$\begin{array}{l}\text { activity after } 6 \text { months } \\
\text { of treatment }\end{array}$ & $\begin{array}{c}\text { Oral } \\
(n=25)\end{array}$ & $\begin{array}{l}\text { Subcutaneous } \\
(n=25)\end{array}$ & \\
Number of joints with active arthritis & $1.6 \pm 1.2$ & $0.5 \pm 0.2$ & 0.001 \\
Number of joints with limited range of motion & $1.0 \pm 0.2$ & $0.5 \pm 0.1$ & 0.035 \\
Patient/Parents' global assessment $(0-10 \mathrm{~cm})$ & $3.6 \pm 1.4$ & $1.5 \pm 0.3$ & $<0.001$ \\
Physician's global assessment $(0-10)$ & $3.8 \pm 1.8$ & $1.6 \pm 0.4$ & $<0.001$ \\
C-HAQ disability index (0-3) & $0.4 \pm 0.1$ & $0.0 \pm 0.0$ & 0.002 \\
ESR & $30.2 \pm 13.3$ & $19.7 \pm 5.3$ & 0.001
\end{tabular}

\section{Outcome after $\mathbf{6}$ months of treatment:}

All the children in the Subcutaneous group and majority (84\%) in the Oral group achieved ACR 30 Pedi criteria after 6 months of treatment with MTX. None of the children needed to switch from oral group (either due to inefficacy or intolerance or remission) to subcutaneous group. Two patients in the Subcutaneous group discontinued, though reasons of discontinuation were not reported. Majority of the children in either group experienced adverse events with no significant intergroup difference $(p=0.748)$ (Table $V)$. 


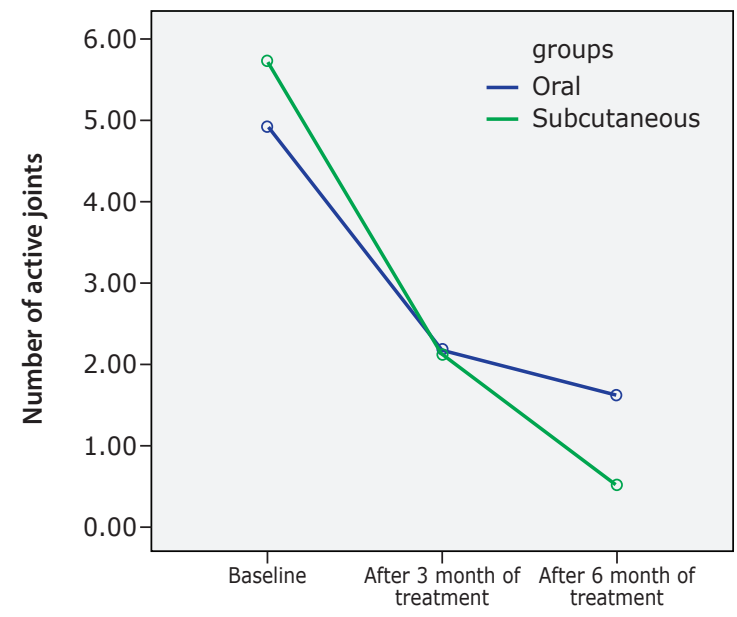

Fig: 1 Level of evaluation

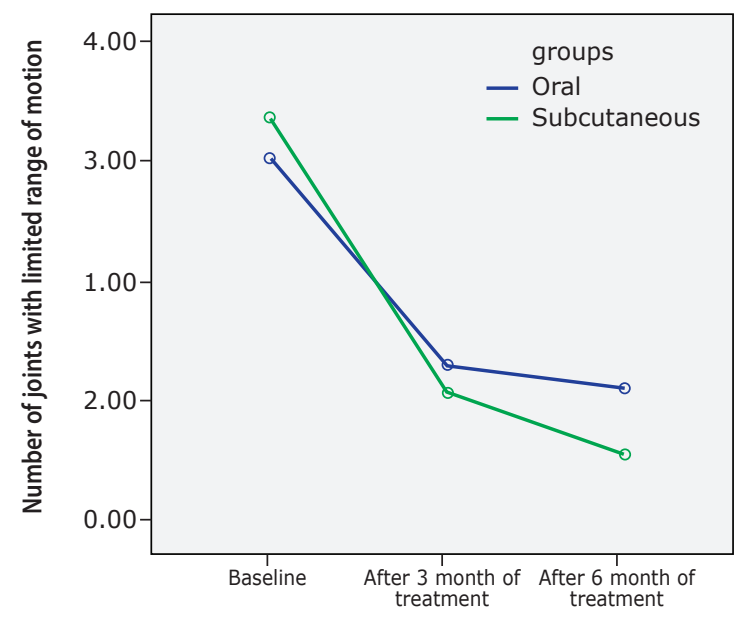

Fig: 2 Level of evaluation

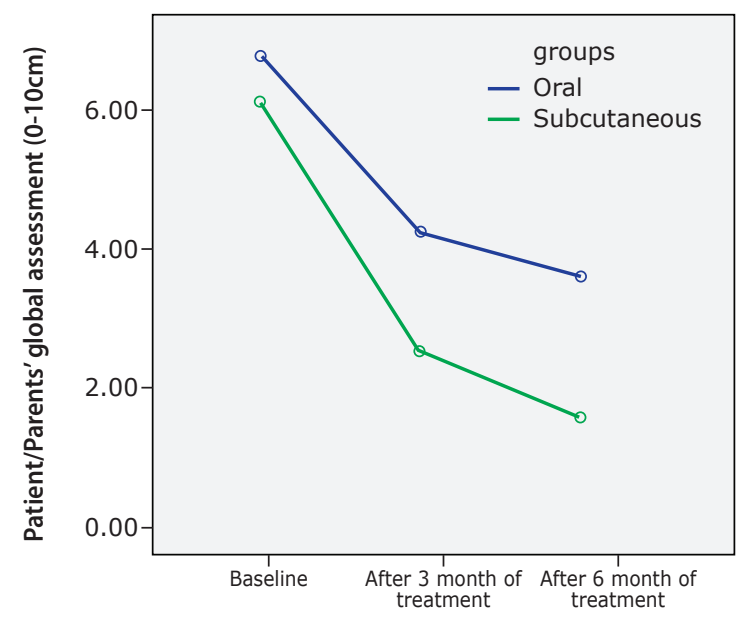

Fig: 3 Level of evaluation

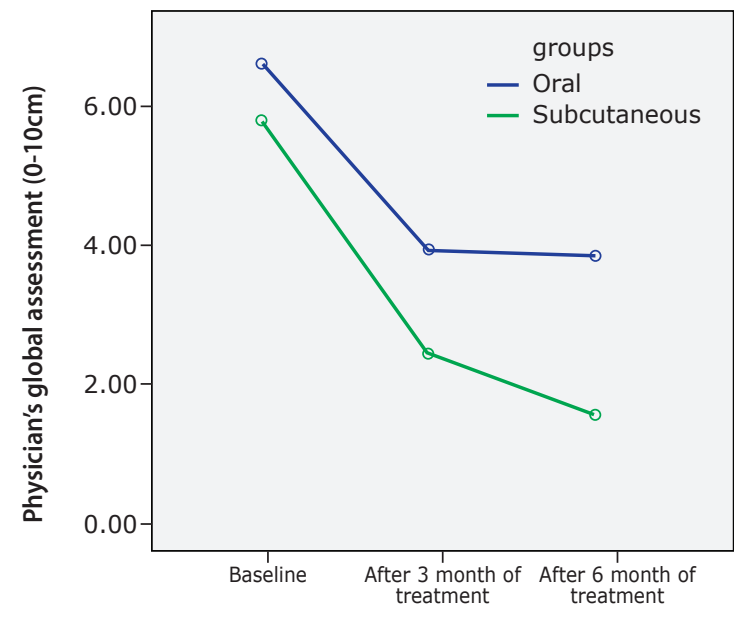

Fig: 4 Level of evaluation

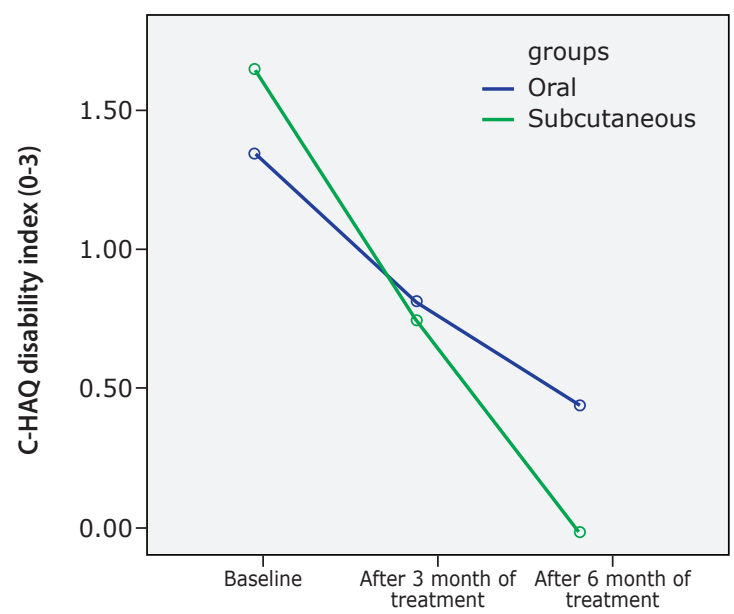

Fig: 5 Level of evaluation

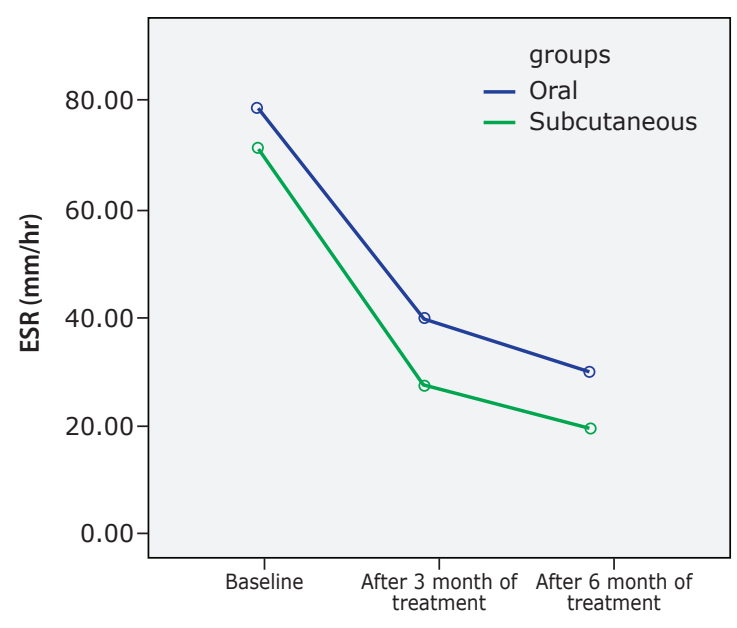

Fig: 6 Level of evaluation

Fig: Figure 1-6 showing changes in disease activity from baseline to 6 months following intervention. 
All the ADEs were minor in nature with GI symptoms being significantly higher in the Oral group than that in the Subcutaneous group ( $p=$ 0.001 ). While the incidence of elevated liver enzymes was higher in the Oral group ( $p=$ 0.034 ), the incidence of skin rash or dermatitis was much higher in the Subcutaneous group ( $p=$ 0.001) (Table VI).

\begin{tabular}{|c|c|c|c|}
\hline \multirow{2}{*}{$\begin{array}{l}\text { Outcome after } 6 \text { months } \\
\text { of treatment }\end{array}$} & \multicolumn{2}{|c|}{ Group } & \multirow{2}{*}{ p-value } \\
\hline & $\begin{array}{c}\text { Oral } \\
(n=25)\end{array}$ & $\begin{array}{l}\text { Subcutaneous } \\
\qquad(\mathrm{n}=24)\end{array}$ & \\
\hline ACR 30 Pedi criteria achieved* & $21(84.0)$ & $25(100.0)$ & 0.110 \\
\hline Discontinuation of treatment ${ }^{* *}$ & $0(0.0)$ & $2(8.0)$ & 0.149 \\
\hline Adverse events* & $22(88.0)$ & $20(80.0)$ & 0.748 \\
\hline
\end{tabular}

\begin{tabular}{|c|c|c|c|}
\hline \multicolumn{4}{|c|}{$\begin{array}{l}\text { TABLE VI. Comparison of types of adverse events between } \\
\text { groups }\end{array}$} \\
\hline \multirow[b]{2}{*}{ Adverse events } & \multicolumn{2}{|c|}{ Group } & \multirow[b]{2}{*}{$p$-value } \\
\hline & $\begin{array}{c}\text { Oral } \\
(n=25)\end{array}$ & $\begin{array}{l}\text { Subcutaneous } \\
\qquad(\mathrm{n}=25)\end{array}$ & \\
\hline \multicolumn{4}{|l|}{ Non-serious } \\
\hline Gl symptoms* & 18(72.0) & $10(40.0)$ & 0.001 \\
\hline Infectious events* & $6(24.0)$ & $7(28.0)$ & 0.747 \\
\hline Elevated liver enzymes* & $11(44.0)$ & $4(16.0)$ & 0.034 \\
\hline Skin rash/dermatitis* & $2(8.0)$ & $13(52.0)$ & 0.001 \\
\hline Others** & $2(8.0)$ & $0(0.0)$ & 0.149 \\
\hline
\end{tabular}

Figures in the parentheses indicate corresponding \%; *Chi-squared Test $\left(\chi^{2}\right)$ was done to analyze the data.

**Fisher's Exact Test was done to analyzed the data.

\section{DISCUSSION:}

The aim of modern treatment of JIA is rapid induction of disease control to prevent joint damage in order to maximize physical function and to achieve a normal lifestyle. ${ }^{17}$ To that end a number of DMARDs (methotrexate (MTX), sulfasalazine, hydroxychloroquine, leflunomide and cyclosporine etc.) are commonly used. Over the years low-dose weekly methotrexate has become the cornerstone disease-modifying anti-rheumatic drug in juvenile idiopathic arthritis (JIA), because of its efficacy. ${ }^{18}$ However, the issue that which route of administration is most suitable for the treatment of JIA in terms of efficacy and safety profile has not yet been solved. The present study was performed to compare the efficacy and safety of low-dose MTX in the treatment of JIA using oral and subcutaneous route.

In the present study there was no significant difference between the study groups in terms of age, sex, weight and duration of disease $(p=0.330, p=0.395, p=$ 0.883 and $p=0.891$ respectively). Most of the core set of parameters were well-matched except that the patients of oral MTX treatment group had significantly higher scores for physician global assessment of disease activity $(p=0.011)$. The study demonstrated that children with JIA responded well to MTX treatment irrespective of their route of administration, as was evidenced by the achievement of ACR Pedi 30 criteria by majority of the children after 6 months of treatment. However, if we analyze the response of core set of variables, it appears that subcutaneous route worked better and faster than the oral route did.

To know the reasons why subcutaneous route works faster, we have to know the pharmacodynamiocs of MTX. The pharmacokinetics of MTX has been studied extensively. ${ }^{15,19,20}$ It is the bioavailability of a drug which determines its efficacy. The bioavailability of higher oral doses of MTX in adult patients with RA is highly variable and, on average, is two-thirds that of subcutaneous (SC) or intramuscular (IM) administration. ${ }^{15,19}$ Some studies, however, have suggested that IM MTX showed improved clinical efficacy with fewer side effects compared with oral MTX. ${ }^{21-23}$ Contrary to the findings in adults, only few studies have examined pharmacokinetics of oral MTX in children with JIA. ${ }^{24-25}$ However, when taken orally, food interferes the absorption of MTX and reduces its peak concentration and slightly increases the time to peak concentration of MTX. ${ }^{19}$ Considerable interindividual variability in the rate and extent of absorption and reduced bioavailability of MTX may limit clinical use of oral MTX and justify switch to parenteral routes of administration (subcutaneous or intramuscular) in patients with inadequate clinical response as was observed in Klein et al's study. ${ }^{13}$

In children with JIA, MTX therapy is commonly started at a dose of 10 to $15 \mathrm{mg} / \mathrm{m}^{2}$ and is administered weekly, either orally or parenterally (subcutaneously or intramuscularly). In our study we used $10 \mathrm{mg} / \mathrm{m}^{2}$ weekly in both groups. Routine therapeutic monitoring of MTX after oral administration is not recommended because MTX blood concentrations have been shown to 
have wide interpatient and intrapatient variability. ${ }^{26}$ At the standard dose regimen, 60 to $70 \%$ of patients with JIA benefit significantly from MTX therapy, with the maximum therapeutic effect usually becoming apparent 4 to 6 months after the beginning of treatment. Children experiencing adverse events were common. All the ADEs were minor in nature. Collectively there was no significant difference between the groups in terms of AEDs. While, GI symptoms and elevated liver enzymes were significantly higher in the Oral group, skin rash or dermatitis was frequently common in the Subcutaneous group. In general, children tolerate MTX well. However, although serious toxicity is uncommon, a prevalence of adverse events as high as $42 \%$ has been reported. Common side effects include GI toxicity (nausea, anorexia, stomatitis) and transient elevation of serum aminotransferase levels. ${ }^{27}$ None of the children required to be switched from oral group (either due to inefficacy or intolerance or relapse) to subcutaneous group. Two patients in the Subcutaneous group discontinued, though reasons of discontinuation remained obscured.

The issues of when, how, and by what criteria to discontinue MTX are critical for children with JIA. Currently, there is no widely accepted definition for remission in JIA. Reported rates of remission in JIA treated with MTX vary from 6.9 to $45 \%$; the average duration of MTX treatment until remission is around one year at $10-15 \mathrm{mg} / \mathrm{m}^{2}$ weekly dose. ${ }^{25}$ Due to concerns from the earlier MTX era about the risk of longterm liver toxicity, in the past MTX was often discontinued shortly after complete disease control was achieved. However, a high frequency of relapse after MTX withdrawal among these patients was observed, particularly in those with oligoarticular onset and polyarticular course (extended oligoarticular subtype). ${ }^{28}$ At present, most investigators favour continuing MTX therapy longer after clinical remission is achieved. However, there are no guidelines regarding length of MTX treatment after remission. Furthermore, it is not established whether the dosage and frequency of administration should remain stable or gradually decrease. The current policy is to continue MTX at a weekly regimen and unchanged dosage for 6 months after the achievement of a sustained remission, and then taper it until discontinuation by spacing the same weekly dosage further apart over an additional 6 months.

\section{CONCLUSION:}

The study concluded that children with JIA responded well to MTX treatment irrespective of their route of administration, as was evidenced by the achievement of ACR Pedi 30 criteria by majority of the children after 6 months of treatment. However, considering the response in terms of core set of variables, it appears that subcutaneous route worked better and faster than the oral route did. So the option for route of administration should be left to the treating pediatricians until definite recommendations for the route of administration of MTX treatment come out from randomized controlled trials in JIA.

\section{REFERENCES:}

1. Petty RE, Southwood TR, Manners P, Baum J, Glass DN, Goldenberg J, et al. International League of Associations for Rheumatology. International League of Associations for Rheumatology classification of juvenile idiopathic arthritis: second revision, Edmonton, 2001. J Rheumatol $2004 ; 31: 390-2$.

2. Ravelli A, Martini A. Juvenile idiopathic arthritis. Lancet 2007;369:767-78.

3. Danner S, Sordet C, Terzic J, Donato L, Velten M, Fischbach $M$, et al. Epidemiology of juvenile idiopathic arthritis in Alsace, France. J Rheumatol 2006;33:1377-81.

4. Zink A, Listing J, Niewerth $M$, Zeidler $H$, for the German Collaborative Arthritis Centres. The national database of the German Collaborative Arthritis Centres. II. Treatment of patients with rheumatoid arthritis. Ann Rheum Dis 2001;60:207-13.

5. Giannini EH, Brewer EJ, Kuzmina N, Shaikov A, Maximov A, Vorontsov I, et al. Methotrexate in resistant juvenile rheumatoid arthritis: results of the U.S.A.- U.S.S.R. double-blind, placebo-controlled trial. $N$ Engl J Med 1992;326:1043-9.

6. Woo P, Southwood TR, Prieur AM, Dore CJ, Grainger J, David J, et al. Randomized, placebo-controlled, crossover trial of low-dose oral methotrexate in children with extended oligoarticular or systemic arthritis. Arthritis Rheum 2000;43:1849-57.

7. Ruperto N, Murray KJ, Gerloni V, Wulffraat N, de Oliveira SK, Falcini $F$, et al, for the Pediatric Rheumatology International Trials Organization. A randomized trial of parenteral methotrexate comparing an intermediate dose with a higher dose in children with juvenile idiopathic arthritis who failed to respond to standard doses of methotrexate. Arthritis Rheum 2004;50:2191-201. 
8. Guellac N, Niehues T. Interdisciplinary and evidence-based treatment guideline for juvenile idiopathic arthritis. Klin Padiatr 2008;220:392-402.

9. Bader-Meunier B, Wouters C, Job-Deslandre C, Cimaz R, Hofer $M$, Pillet $P$ et al. Guidelines for diagnosis and treatment of oligoarticular and polyarticular juvenile idiopathic arthritis. Arch Pediatr 2010;17:1085-9.

10. Beukelman T, Patkar NM, Saag KG, Tolleson-Rinehart S, Cron $R Q$, DeWitt EM et al. American College of Rheumatology recommendations for the treatment of juvenile idiopathic arthritis: initiation and safety monitoring of therapeutic agents for the treatment of arthritis and systemic features. Arthritis Care Res (Hoboken) 2011;63:465-82.

11. Braun J, Kastner P, Flaxenberg P, Wahrisch J, Hanke P, Demary W et al, for the MC-MTX.6/RH Study Group. Comparison of the clinical efficacy and safety of subcutaneous versus oral administration of methotrexate in patients with active rheumatoid arthritis: results of a six-month, multicenter, randomized, double-blind, controlled, phase IV trial. Arthritis Rheum 2008;58:73-81.

12. Alsufyani K, Ortiz-Alvarez O, Cabral DA, Tucker LB, Petty RE, Malleson PN. The role of subcutaneous administration of methotrexate, in children with juvenile idiopathic arthritis who have failed oral methotrexate. J Rheumatol 2004;31:179-82.

13. Klein A, Kaul I, Foeldvari I, Ganser G, Urban A, Horneff G. Efficacy and Safety of Oral and Parenteral Methotrexate Therapy in Children With Juvenile Idiopathic Arthritis: An Observational Study With Patients From the German Methotrexate Registry Arthritis Care \& Research 2012;64(9):1349-56.

14. Hamilton RA, Kremer JM. Why intramuscular methotrexate may be more efficacious than oral dosing in patients with rheumatoid arthritis. Br J Rheumatol 1997;36:86-90.

15. Hoekstra M, Haagsma C, Neef C, Proost J, Knuif A, van de Laar M. Bioavailability of higher dose methotrexate comparing oral and subcutaneous administration in patients with rheumatoid arthritis. J Rheumatol 2004;31:645-8.

16. Giannini EH, Ruperto N, Ravelli A, Lovell DJ, Felson DT, Martini A. Preliminary definition of improvement in juvenile arthritis. Arthritis Rheum 1997;40:1202-9.
17. Ramanan AV, Whitworth P, Baildam EM. Use of methotrexate in juvenile idiopathic arthritis. Arc Dis Child 2003;88:197-200.

18. Ramanan AV, Ravelli A, Martini A. Methotrexate in Juvenile Idiopathic Arthritis. J Rheumatol 2000;27:1830-33.

19. Hamilton RA, Kremer JM. Why intramuscular methotrexate may be more efficacious than oral dosing in patients with rheumatoid arthritis. Br J Rheumatol 1997;36:86-90.

20. Oguey D, Kolliker F, Gerber NJ, Reichen J. Effect of food on the bioavailability of low-dose methotrexate in patients with rheumatoid arthritis. Arthritis Rheum 1992;35:611-4.

21. Rozin A, Schapira D, Balbir-Gurman A, Braun-Moscovici $Y$, Markovits D, Militianu D, et al. Relapse of rheumatoid arthritis after substitution of oral for parenteral administration of methotrexate. Ann Rheum Dis 2002;61:756-7.

22. Bingham SJ, Buch MH, Lindsay S, Pollard A, White J, Emery P. Parenteral methotrexate should be given before biological therapy. Rheumatology (Oxford) 2003;42:1009-10.

23. Wegrzyn J, Adeleine P, Miossec P. Better efficacy of methotrexate given by intramuscular injection than orally in patients with rheumatoid arthritis. Ann Rheum Dis 2004;63:1232-4.

24. Albertioni F, Flatø B, Seideman P, Beck O, Vinje O, Peterson C et al. Methotrexate in juvenile rheumatoid arthritis. Eur J Clin Pharmacol 1995;47:507-11.

25. Kimura E, Oga S, Pereira RM. Comparative study of the pharmacokinetics of MTX in juvenile idiopathic arthritis patients receiving long-term MTX monotherapy or MTX plus chloroquine. J Clin Pharm Ther 2007;32:579-84.

26. Ravelli A, Di Fuccia G, Molinaro M, Ramenghi B, Zonta L, Regazzi MB et al. Plasma levels after oral methotrexate in children with juvenile rheumatoid arthritis. I Rheumatol 1993;20:1573-7.

27. Ravelli A, Gerloni V, Corona F, Falcini F, Lepore L, De Sanctis $R$ et al. Oral versus intramuscular methotrexate in juvenile chronic arthritis. Clin Exp Rheumatol 1998;16(2):181-3.

28. Ravelli A, Viola S, Ramenghi B, Aramini L, Ruperto N, Martini A. Frequency of relapse after discontinuation of methotrexate therapy for clinical remission in juvenile rheumatoid arthritis. J Rheumatol 1995;22:1574-6. 